\title{
AN EXAMINATION OF SENSE OF CLASSROOM COMMUNITY AND LEARNING AMONG AFRICAN AMERICAN AND CAUCASIAN GRADUATE STUDENTS
}

\author{
Alfred P. Rovai \\ School of Education, Regent University \\ Michael K. Ponton \\ School of Education, Regent University
}

\begin{abstract}
Higher education administrators and faculty members seek ways in which to advance student learning in online courses, and student affairs professionals seek ways to promote a sense of belonging and connectedness of students to their schools. The present study examined how a set of three classroom community variables were related to a set of two student learning variables in a predominantly White sample of 108 online African American and Caucasian graduate students. Using canonical correlation, the two subscales of the Classroom Community Scale and the mean number of messages posted each week to the online course's group discussion boards were found to be related significantly to perceived learning and total points earned in the course along a single dimension. Moreover, African American students scored significantly lower across all five variables than their Caucasian peers, suggesting that the achievement gap that exists in many traditional educational programs also exists in graduate ALN programs and that this gap extends to sense of community.
\end{abstract}

\section{KEY WORDS}

Sense of Community, Learning, Higher Education, African American, Caucasian

\section{INTRODUCTION}

Distance education has burgeoned over the past decade and it continues to rapidly expand [1]. The anytime, anywhere delivery of courses by computer networks, known as Asynchronous Learning Networks (ALNs), has become the most popular medium used by U. S. higher education for delivering courses at a distance [2]. Moreover, ALNs are a viable alternative for students who either cannot or choose not to travel to campuses to attend traditional class meetings at predetermined times. This mode of distant learning is often an attractive option for African American students because they are likely to be employed full-time and choose the scheduling convenience of ALN programs over traditional programs [3].

Research suggests that distance education programs are best suited for certain types of students. Often cited characteristics of successful students include being a self-motivated, independent, and self-directed learner; a critical thinker; a good time manager; and a highly organized individual [e.g., 4, 5, 6]. Consequently, deficiencies in any of these factors, either singly or in combination, may adversely affect educational outcomes in ALN courses. Moreover, insufficient interactions of students with peers and faculty and differences with the prevailing value patterns of other students are likely to result in students 
who feel they do not fit in, which, in turn, may result in a weak sense of community due to lack of engagement, feelings of isolation, and poor academic performance [7].

The purpose of the present study was to examine the relationship of sense of community and learning in an ALN graduate program and to identify differences, if any, between African American and Caucasian students regarding these variables. Most of the past research regarding the so-called achievement gap has taken place using a traditional educational setting. The present study extends research to determine if an ALN educational environment offered by a predominantly White university differentially influences sense of community and learning between African American and Caucasian students. To narrow and eventually eliminate achievement gaps, we first must understand these gaps.

Students of African American heritage have been at the center of a long standing debate to explain the academic underperformance of many minority students. Many researchers believe that the source of the problem is in the educational environment and/or cultural values [e.g., 8, 9]. In particular, John Ogbu, a noted anthropologist, examined multicultural educational outcomes in terms of communication theory [9]. He suggested that students enter the classroom with modes of interaction that reflect their home culture and that often conflict with the culture of the school. Since communication is central to educational processes, effective communication is essential to the reduction of potential problems associated with the clash of cultures in the classroom and to ensure the establishment of an appropriate teaching/learning environment. This is particularly important in ALN programs, where communication is mostly written and often represents the only contact between classroom community members. Ogbu theorized that the academic environment must be facilitated by cultural connections identifying and linking communication as a significant element in the teaching and learning process [9]. As such, cultural contexts are essential to communication effectiveness.

A multitude of scholars [e.g., 8, 9, 10, 11, 12, 13] argued that differences in Black and White cultures suggest different learning style preferences, which can cause stress in African American students who enter predominantly White schools. They suggested that many Black students employ people-oriented, relational, and field dependent approaches to learning rather than the independent and analytical style favored by White students, which research also suggests is a style characteristic of successful distance education students [e.g., 4, 5, 6].

Field dependent learners prefer student-centered, more personal environments where learning is related to the life experiences of the student and is neither abstract nor isolated, whereas field independent learners are more interested in concepts for their own sake and prefer to work in independent, impersonal environments [14]. Consequently, African American students who tend to prefer a more dependent learning style may be less academically successful in online learning environments, in which independent learning is a characteristic of a successful learner, than their White peers who tend to prefer the independent learning style. Additionally, differences in cultural backgrounds and associated social values may be barriers to forming a strong sense of community and to academic success in multicultural classroom environments [7]. These factors suggest that the achievement gap by race is likely to manifest itself in ALN programs, particularly those that are not designed to reach out to students with diverse learning styles.

\section{A. Classroom Community}

Human behavior is not independent of the social world in which we live. Crude theories of psychology, such as radical behaviorism, adopt a mechanistic perspective of human functioning in which people robotically respond to external stimuli without cognitive mediation. On the other hand, social cognitive 
theory posits that intentional activity (i.e., human agency) is predicated on the reciprocal interaction between personal behavior, internal personal factors (i.e., biology, cognition, affection), and the environment [15]. The specific degree to which each bidirectional interaction influences agency depends upon the context of the activity under consideration. These interactions influence motivation and selfbeliefs, which are a part of the self-regulatory system that each individual possesses. This self-regulatory system aids in the development of beliefs and behavior that will enable or discount actions.

Adult education is influenced by the environment created by both the instructor and the students where the environment is both real (the objective influence of behavior on the environment) and imagined (the subjective influence of internal personal factors on the environment). Reciprocal determinism suggests that it is this resultant environment, not merely an objectively described one, which will affect human performance and shape internal thought processes [16]. Thus, properly constructed educational environments should be able to foster a sense of community where this sense will influence environmental ideation, subsequent behavior, and interpretations of behavioral results. Self-reflective interpretations of behavioral consequences (of which sense of community is only one) will influence subsequent thought processes and ultimate levels of achievement [17].

During the past decade, the professional literature has given increased attention to the role of sense of community in educational outcomes. Schools include communities where members are committed to thinking, growing, and inquiring and where learning is an attitude as well as an activity [18]. There is a need for authentic community, a tie binding learners and teachers through shared values, ideals, and goals. Despite the existence of a large body of literature on sense of community, there is no universally accepted definition of the term; however, the literature contains several useful conceptualizations. One definition views virtual community as "social aggregations that emerge from the [Internet] when enough people carry on ... public discussions long enough with sufficient human feeling, to form personal relationships in cyberspace" [19,].

Strong feelings of classroom community can increase the flow of information, the availability of support, commitment to group goals, sense of well-being, cooperation among members, and satisfaction with group efforts [20,21]. In a traditional high school environment, sense of community was directly related to interest in academics and learning and inversely related to student misbehavior and dropout rates [22]. Students who reported a strong sense of community also felt less burned out at school [23]. Students often point to the sense of community that existed within their classes when asked to name the most critical factor in surviving a challenging educational experience [24].

\section{B. Learning}

Learning is the change in one's capability or knowledge [25]. It has important social and cognitive dimensions and appears to occur most effectively in structured educational programs when there is a strong sense of community [e.g., 22]. Learning is considered "an integral and inseparable aspect of social practice” within the classroom community [26,]. Rather than merely adding to the student's knowledge, learning involves a "process of transformation of participation itself," which occurs as a function of all active members of the classroom community "transforming roles and understanding in the activities in which they participate" [27]. The essence of community spirit in a classroom setting is clearly seen when one defines a community of practice as a group of people who share a concern, a set of problems, or a passion about a topic, and who deepen their knowledge and expertise in this area by interacting on an ongoing basis [28]. 
Studies of online environments have provided evidence that one can create a sense of community and sustain strong ties through electronic media [e.g., 29, 19]. As in a traditional classroom, an online classroom community is not just a network of individuals. A sense of community binds students together in a comfortable collaborative learning environment in which they assume a sense of ownership for the academic goals of the group. Members of strong online communities support common goals [29, 30]; they establish their own hierarchies of expertise and modes of interaction [31] and share a common history and a common meeting place in the form of the virtual classroom. Rules of behavior and a shared history provide an identity for the group and a way of knowing how to behave and how to anticipate the behavior of others [30]. However, Rena Palloff and Keith Pratt warn that it is possible to develop a strong sense of community in an online virtual classroom where very little learning occurs [32]. They, therefore, suggested that it is important for online professors to be actively engaged in the learning process and to guide participants who stray from the learning goals, thus ensuring that a strong learning community emerges, not just a strong social community.

Online conferencing environments, such as online discussion boards, are effective for students to coconstruct social meaning [33]. What is not fully understood is if and how sense of community is related to learning in online classroom environments. Although empirical research evidence exists to support a relationship between these variables in traditional face-to face classroom environments [e.g., 22, 23], little evidence exists regarding how these variables are related to each other in ALNs.

\section{METHODOLOGY}

\section{A. Participants}

The participants for the present study consisted of 108 students enrolled in an online Doctor of Education program. The volunteer rate for this study was 96\%. The sample consisted of 96 (88.9\%) females and 12 (11.1\%) males. A total of 40 participants (37.0\%) were African American, 64 (59.3\%) were Caucasian, and 4 (3.7\%) classified themselves as other. All participants were employed in the field of education as either a teacher or administrator, with the majority working in the $\mathrm{K}-12$ school environment.

\section{B. Setting}

Participants were enrolled in an online graduate educational research methodology course worth three semester credits. The goals of this course were for students to develop (a) an appreciation for the usefulness of research in studying social phenomena; (b) a sophisticated understanding of quantitative and qualitative research methods; and (c) the skills necessary to plan, conduct, and critique educational research. The course was delivered by a small, private university located in an urban area of the Commonwealth of Virginia. The course was one semester (i.e., 16 weeks) in duration and was taught by the same Caucasian professor entirely via the Internet using the Blackboard ${ }^{\mathrm{SM}}$ e-learning system. This ALN system consists of an integrated set of mostly asynchronous application tools that were accessible to students via the Internet.

Four sections of the course were sampled, with no section having more than 30 students. Each week students were presented with two or three instructional tasks: (a) reading assignments in the course textbook and Web-based professor's notes; (b) a weekly collaborative online discussion assignment using group discussion boards and consisting of 12 to15 students per group; and (c) the evaluation of an authentic case study requiring individual work. The instructor encouraged active and purposeful interaction between community members and course participation accounted for 10 percent of the overall course grade. Criteria for a discussion grade of " $A$ " included accessing the group discussion board multiple times per week, reading all posted messages, and posting at least two or three constructive 
messages each week. Students were requested to direct comments primarily to other students rather than to the instructor and to show evidence of support and encouragement in their postings, as well as a willingness to critically evaluate the work of others with constructive comments.

The classes were all designed and taught in an active and user-friendly, password-protected learning environment. The professor used a pedagogy that emphasized the construction of knowledge through discussion [33] and collaborative group work. The professor reported that he used the expert, formal authority, personal model, and facilitator teaching styles [34], which provide matches for both dependent and independent learners. The expert is a transmitter of information; the formal authority professor sets standards and defines acceptable ways of doing things; the personal model teaches by illustration and direct example; and the facilitator guides and directs by asking questions, exploring options, suggesting alternatives. The expert, formal authority, and personal model teaching styles are good strategies for dependent learners while the expert, facilitator, and personal model teaching styles are good strategies for independent learners [34].

\section{Instrumentation}

Two sets of variables were utilized in the present study. Social community, learning community, and mean number of messages posted weekly to group discussion boards were used to evaluate classroom community. Total course points and perceived learning were used to address student learning.

\section{Classroom Community Set}

The Classroom Community Scale (CCS) was used to measure feelings of connectedness (i.e., social community) and feelings about learning and educational goal satisfaction (i.e., learning community) [35]. Social community represents the feelings of a community of students regarding their cohesion, spirit, trust, interdependence, and social presence. Learning community represents the feelings of community members regarding the degree to which they share educational goals and the capacity of the classroom community to support learning and educational goal satisfaction.

This instrument consisted of 20 self-report items, such as I feel isolated in this course and I feel that this course is like a family. Following each item was a five-point Likert scale of potential responses: Strongly agree, Agree, Neutral, Disagree, and Strongly disagree. The CCS produced social community and learning community subscales. Scores on each subscale can range from 0 to 40, with higher scores reflecting a stronger sense of community.

The results of a factor analysis confirmed that the two subscales were latent dimensions of the classroom community construct [35]. Cronbach's coefficient alpha for the full classroom community scale was .93. Additionally, the internal consistency estimates for the social community and learning community subscales were .92 and .87 , respectively. In the present study, Cronbach's coefficient alpha for the full classroom community scale and the social community and learning community subscales were .93, .91, and .84 , respectively.

The mean number of messages posted weekly to group discussion boards was also used to measure sense of community, with larger numbers of postings suggesting stronger feelings of community as evidence of an increased level of engagement. The messages posted by students to group discussion boards were recorded and reported by the Blackboard ${ }^{\mathrm{SM}}$ e-learning system. 


\section{Student Learning Set}

Student grades are the most prevalent measure of student learning outcomes used by educational researchers [36]. Accordingly, total course points were also used as a measure of student learning in the present study. Total possible points ranged from 0 to 100 . The course syllabus identified the range for $\mathrm{A}$ and A- work as 93 to 100 points; B+, B, and B- work ranged from 81 to 92 points; $\mathrm{C}+$ and $\mathrm{C}$ work ranged 73 to 80 points; and $\mathrm{F}$ work was below 73 points. Course participation accounted for $10 \%$ of the total course points while grades on individual assignments accounted for the remaining $90 \%$.

However, grades can have a limited relationship to what students have learned. Students may already know the material when they enroll or their grade may be more related to class participation or work turned in late. Consequently, perceived learning was also used as a measure of student learning in the present study. There is a considerable amount of literature concerned with establishing the validity of student self-reports of cognitive outcomes that suggest self-reports of cognitive gain are indicative of results obtained through more direct forms of assessment [37].

The perceived learning instrument used in this study been used in many studies related to learning outcomes [38]. Participants were asked to respond to the following item: On a scale of 0 to 9, how much did you learn in this course, with 0 meaning you learned nothing and 9 meaning you learned more than in any other course you've had? Test-retest reliability over a five-day period was .85 in a study of 162 adult learners [39]. Internal consistency reliability was not applicable since the instrument consists of only one item.

\section{Procedures}

The CCS and perceived learning measure were made available to participants via an online survey during the final three weeks of the semester to enable them to have substantial exposure to their respective classes. Total course points and number of messages posted to group discussion boards were obtained at the end of the semester. Participants did not know their final course grade when they completed the perceived learning measure.

\section{E. Design and Data Analysis}

Two research questions were examined in the present study. For the first question, a correlational design was used to determine if and how the set of three variables that measured sense of community in an online classroom setting were related to the set of two student learning variables. Canonical correlation was used to analyze the data. The goal of this analysis was to maximize the relationship between the two sets of variables and to determine the number of dimensions on which they were possibly related. The variance of the original two sets of variables was redistributed into pairs of canonical variates (i.e., functions) that maximized the correlation between the two sets. Specific procedures used in this analysis are described in the results section below.

For the second research question, a causal-comparative design was used to determine if the three community variables and two learning variables differed by culture (African American and Caucasian). A one-way multivariate analysis of variance (MANOVA) was used to analyze the data for this question. Effect size was calculated using the eta squared $\left(\eta^{2}\right)$ statistic and interpretation was based on thresholds of .01 for a small effect, .06 for a moderate effect, and .14 for a large effect [40]. Assumptions tested and specific statistical procedures used in the analyses are described in the following section. 


\section{RESULTS}

The pooled means (with standard deviations in parentheses) for social community, learning community, and mean number of postings per week were 27.67 (7.04), 31.04 (5.57), and 5.63 (3.13), respectively. For social community, scores ranged from a low of 13.00 to a high of 38.00; for learning community, the range was 18.00 to 39.00; and for mean postings per week, the range was 1.50 to 15.10 . The pooled means (with standard deviations in parentheses) for course points and perceived learning were 87.53 (6.70) and 7.00 (1.37), respectively. Course points scores ranged from a low of 65.20 (a letter grade of F) to a high of 97.70 (a letter grade of A) and perceived learning ranged from 4.00 to 9.00. Descriptive statistics disaggregated by race are displayed in Table 1. Pearson bivariate correlations for the five variables used in this study are displayed in Table 2. All correlations were significant at the .05 level.

\begin{tabular}{|c|c|c|c|c|}
\hline & \multicolumn{2}{|c|}{ African American } & \multicolumn{2}{|c|}{ Caucasian } \\
\hline Variable & M & $\mathrm{SD}$ & M & SD \\
\hline \multicolumn{5}{|c|}{ Classroom community set } \\
\hline Social community & 25.10 & 7.45 & 29.18 & 6.37 \\
\hline Learning community & 27.50 & 5.55 & 33.12 & 4.45 \\
\hline Mean postings/week & 3.82 & 2.44 & 6.69 & 3.01 \\
\hline \multicolumn{5}{|c|}{ Student learning set } \\
\hline Course points & 84.05 & 8.15 & 89.57 & 4.65 \\
\hline Perceived learning & 6.20 & 1.42 & 7.47 & 1.10 \\
\hline \multicolumn{5}{|c|}{$\begin{array}{l}\text { Note: The two subscales of the CCS can each range from } 0 \text { to } \\
\text { 40, with higher scores reflecting a stronger sense of community. } \\
\text { The perceived learning measure can range from } 0 \text { to } 9 \text { and } \\
\text { course points can range from } 0 \text { to } 100 \text {, with higher scores } \\
\text { reflecting greater learning. }\end{array}$} \\
\hline
\end{tabular}

Table 1. Descriptive Statistics Disaggregated by Race

\begin{tabular}{lccccc}
\hline & 1 & 2 & 3 & 4 & 5 \\
\hline 1. Social community & - & .82 & .55 & .56 & .32 \\
2. Learning community & & - & .59 & .66 & .44 \\
3. Mean postings & & & - & .31 & .39 \\
4. Course points & & & & - & .20 \\
5. Perceived learning & & & & & - \\
\hline Note: $p<.05$. & & & & \\
\hline
\end{tabular}

Table 2. Correlation Matrix

Canonical correlation assumptions regarding multicollinearity, absence of extreme outliers, homoscedasticity, and linearity were met. Both social community and perceived learning exhibited a distinct negative skew, but were normally distributed based on the results of the one-sample KolmogorovSmirnov test. The first canonical correlation was .74 (55\% overlapping variance) and the second was .23 (5\% overlapping variance). The relationship was significant with both pairs of canonical variates included in the solution, $\chi^{2}(6)=86.39, p<.001$. However, with the first pair of canonical variates removed, $\chi^{2}$ values were not significant, $\chi^{2}(2)=5.60, p=.06$. Therefore, the only significant relationship between the two sets of variables existed in the first pair of canonical variates.

Statistics on the first pair of canonical variates are displayed in Table 3 . Shown in the table are standardized variate coefficients, the structure coefficients (the loadings or bivariate correlations between scores on each variable and the canonical variate for the variable's set), the squared structure coefficients for the first pair of canonical variates, adequacies, redundancies, and the squared canonical correlation 
coefficient. High structure coefficients (i.e., greater than .30) were attained on all variables in both sets. Thus, the significant pair of canonical variates provided evidence that social community, learning community, and mean postings per week co-varied as a set with the set of two student learning variables. There were no suppressor variables in either set since the direction of all relationships was the same. The most useful variables for their respective canonical variates, as reflected by the squared structure coefficients, were learning community, which was $98 \%$ useful for modeling its canonical variate, and perceived learning, which was $81 \%$ useful for modeling its canonical variate. These results suggested that study participants who scored high on all three community variables also scored high on both learning variables, and vice versa. The canonical adequacy coefficients revealed that, on average, the first canonical variate reproduced approximately $67 \%$ of the variance in the three sense of community variables and the second canonical variate reproduced approximately $59 \%$ of the of the variance in the two student learning variables.

\begin{tabular}{lccc}
\hline Variable - statistic & Function & $\mathrm{r}_{\mathrm{s}}$ & $\mathrm{r}_{\mathrm{s}}{ }^{2}$ \\
\hline Social community & .002 & -.82 & .67 \\
Learning community & -1.01 & -.99 & .98 \\
Mean postings/week & .02 & -.58 & .34 \\
Adequacy & & & .67 \\
$\mathrm{Rd}$ & & .36 \\
$\mathrm{Rc}^{2}$ & & .55 \\
$\mathrm{Rd}$ & & .32 \\
Adequacy & -.44 & -.60 & .59 \\
Course points & -.82 & -.90 & .36 \\
Perceived learning & & .81 \\
\hline Note: $N=108 ; \mathrm{r}_{\mathrm{s}}=$ structure coefficient; $\mathrm{r}_{\mathrm{s}}{ }^{2}=$ squared structure coefficient; $\mathrm{Rd}=^{2}$ & \\
redundancy coefficient for a given variable set; Rc ${ }^{2}=$ squared canonical \\
correlation coefficient.
\end{tabular}

A one-way MANOVA was conducted to determine if the three community variables and the two learning variables differed by race (African American and Caucasian). Data screening revealed no univariate or multivariate within-cell outliers at $p<.001$. Results of evaluation of normality, linearity, singularity, and multicollinearity were satisfactory, although the social community and perceived learning distributions were negatively skewed. The overall Wilks' lambda was significant, $\Lambda=.59, F(5,102)=14.19, p<.001$, partial $\eta^{2}=.41$. The multivariate effect size was large.

Post hoc univariate ANOVAs revealed that the African American group scored significantly lower on each of the dependent variables than did the Caucasian group. In particular, for the classroom community set, the results were: social community, $F(1,106)=9.08, p=.003$, partial $\eta^{2}=.08$, learning community, $F(1,106)=33.31, p<.001$, partial $\eta^{2}=.24$, and mean number of postings per week, $F(1,106)=26.21, p$ $<.001$, partial $\eta^{2}=.20$. For the student learning set, the results were: course points, $F(1,106)=20.15, p<$ .001 , partial $\eta^{2}=.16$, and perceived learning, $F(1,106)=27.05, p<.001$, partial $\eta^{2}=.20$. Effect sizes were moderate for social community and large for the remaining dependent variables.

\section{DISCUSSION}

\section{A. Relationship of Community and Learning Variables}

For the first research question, this study sought to determine if and how a set of three variables that 
assessed classroom community were related to a set of two variables that assessed student learning. The results of the canonical correlation analysis were highly interpretable and revealed that the two sets of variables were significantly related to each other along a single dimension. For the classroom community set, both social community and learning community were highly related to the first canonical variate and mean postings per week were moderately related to this variate. For the student learning set, course points were highly related the second canonical variate and perceived learning was moderately related to this variate. Moreover, the two canonical variates were highly related to each other. In other words, participants who possessed both strong feelings of social community and learning community and participated in online discussions by posting more messages to the course discussion board also perceived that they learned more and received higher course grades. The important conclusion for higher education program administrators and faculty is that these findings provide empirical evidence to suggest that sense of community and student learning are highly related constructs in ALN environments.

Another finding of interest was that the bivariate relationship between perceived learning and course points, although significant, was low. Only $4 \%$ of the variance in one variable can be explained by changes in the other. However, perceived learning was highly related to the second canonical variate and course points were moderately related to this same variate. Overall, the second canonical variate reproduced approximately $59 \%$ of the variance in the two student learning variables. Therefore, these two student learning variables captured two substantially different dimensions of the student learning construct and together were highly related to the classroom community construct. The implication for future research is that in dealing with student learning, multivariate analysis, which considers multiple variables simultaneously, can provide richer information than univariate analysis. The use of student grades and perceived learning sheds light on how each variable contributed to the overall student learning construct.

Also of interest was the relatively large variability of classroom community. Within essentially the same learning environment that existed for all four sections of the course, the standard deviation of the social community subscale was $7.04(M=27.67)$. Moreover, out of a possible range of 0 to 40 , the lowest score was 13 and the highest was 38 in a distribution with a pronounced negative skew as well as a flat distribution with a negative standardized kurtosis statistic of -1.75 . The shape of this distribution suggested that there are characteristics and/or traits that each student brings into the online course (e.g., social maturity) that influences feelings of social community. Further research is required to identify these influencing factors. However, comments in the end-of-course student evaluations submitted anonymously suggest information processing learning style may be a moderating variable. For example, one student wrote:

Trying to understand abstract concepts from only printed words in the discussion forums was and is still difficult for me. I have to be able to visualize within a context. I need a more visual approach. I need the professor to draw pictures and diagrams or show slides as he speaks.

Another student also addressed this point by writing:

My thoughts were basically centered around being able to hear conversations about the topics. Face-to-face learning, I know is traditional, but it does provide an opportunity to hear what the professor has to say while also being able to see examples presented. It would be helpful for me to have things explained in detail while I have the samples presented. I understand this can be done online, but I think it's hearing the voices. Sometimes it just feels a little more reassuring to have that auditory input. I also feel that the notes and readings may be explained in greater detail.

The implication for practice is that faculty need to understand that designing and facilitating an online course in ways that promote classroom community may be insufficient to positively affect all members of 
the community of learners. Classroom communities of practice require active leadership to be effective [28] and the primary leader in ALN environments is the online professor [32]. It may be necessary for online faculty to use classroom assessment techniques or to check students' level of participation periodically in order to identify students who may feel isolated or troubled. In some cases the reason may be that the student has insufficient time to devote to the course or perhaps that they need more frequent timely and direct feedback. Thus, the professor's skills in facilitating online discussions are essential to the success of the course. A comment written by one student underscores this point:

[The professor] corrected gaps in understanding immediately when they occurred on Blackboard. This was of great benefit, especially to those individuals who spent large amounts of time on Blackboard. We were able to discuss at length with him any misconceptions or errors in lingo. The level of difficulty of this course is such that the instructor must be vigilant, pointed, and on top of the learners each step of the way, if concepts are to be purely assimilated and applied. I feel that face-to-face is ideal for teaching a course as this, but if (and ONLY if) an instructor can master the online format, as our professor has, is it doable as an online course.

Online students may also acquire negative perceptions that adversely affect their feelings of community. The professor in the present study attempted to enlist a communicator style that was direct, concise, and to the point in order to minimize misunderstandings and manage time in responding to numerous messages each day; however, with limited information and, at times, faulty logic, beliefs structures can be fostered that serve as impediments to success. However, one comment in the end-of-course student evaluations directed to the professor was: "Some of your responses to other students appeared sharp and frank. So instead of calling you, I just depended on my own wit and received help from my colleagues." The potential for such communication problems are high in ALN environments because the text-based computer-mediated communication that is typical in such environments possesses reduced social cues (e.g., voice inflection and facial expressions), which can lead to misunderstandings. In such situations early detection by the professor and a telephone conversation between the professor and student can possibly resolve this problem before it adversely influences student learning.

Within the context of graduate study, course objectives often include fostering autonomy within learners. Such autonomy is manifest in the exhibition of desire, resourcefulness, initiative, and persistence in learning [41], the importance of which is based upon the notion that graduate degrees are dependent upon individual effort and self-regulatory skills. With the expanding presence of nontraditional adult learners in graduate education who often must fulfill a multitude of extracurricular roles that may create impediments to successful matriculation, this notion does not appear to be unrealistic. But because autonomy is conceptually separable from sense of community, it is possible to incorporate instructional methods that develop both. In fact, it is presently asserted that doing so should be a goal of the professor. Students that share the value of developing self-management skills can be both cohesive and capable of demonstrating autonomy. This "community of scholars" can exert communicative influence that strengthens this value while creating expectations for individual effort. Thus, fostering autonomy becomes a shared goal. The instructor facilitates the adoption of this goal by describing its positive relationship to human achievement to the entire group of students, creates performance requirements that require individual effort (even through group work), and opens lines of communication so that through vicarious experiences the value of autonomy is strengthened individually and shared collectively. In other words, a strong sense of community can catalyze interactions that promote autonomy.

Fostering a sense of community is not solely dependent upon the instructor. In fact, there is no reason why a sense of community cannot be enhanced even without the presence of instructor-developed processes. Sense of community is a perception generated by self-reflection of experience. Students who are academically mature may create their own mechanisms (e.g., study groups, e-mail contact, phone 
conversations) that foster cohesion and a shared sense of values. In this regard, pre-existing autonomy can catalyze interactions that promote a sense of community. However, as both autonomy and a sense of community are presently asserted as important to academic success, the instructor should not leave their development to chance but should incorporate instructional strategies that promote both.

\section{B. Gaps in Achievement and Classroom Community}

For the second research question, the present study examined how the three community variables and two learning variables differed by culture (African American and Caucasian) in an ALN environment. Results showed that African American students scored significantly lower across all five variables than their Caucasian peers. Previous research based on largely traditional classroom environments suggested that efforts to close the academic achievement gap between racial minority and Caucasian students have been largely unsuccessful and that differences in educational performance persist at all achievement levels, with the greatest gap between students of color and their White and Asian American peers at higher achievement levels [42]. The present study provided evidence to suggest that this achievement gap also exists in graduate ALN programs. These results are not unexpected, given the substantial research evidence that suggests the course delivery medium is rarely the determining factor for a variety of educational outcomes, including student satisfaction, perceptions, and learning [e.g., 43]. Based on these findings, future research should focus on identification and evaluation of specific online course designs and pedagogies that can close this gap. Given the evidence of the direct relationship of classroom community and learning provided by this study, one area that should be explored is the potential for increasing sense of classroom community among African American students as a strategy for increasing African American achievement and eliminating the achievement gap in online programs.

Differences in cultural backgrounds and associated social values may be barriers to forming a strong sense of community and to academic success in multicultural classroom environments [7, 9]. Consequently, racial issues that influence community in the traditional classroom environment can also affect the virtual classroom, despite the often heard assertion that the Internet erases racial differences and that people are more often judged on their ideas rather than their skin color. For example, it has been suggested that online anonymity can create strong bonds among socially diverse groups [36]. However, The Chronicle of Higher Education reported that many scholars are now beginning to realize that the Internet can also perpetuate racial stereotypes by some users [44]:

Rather than encourage diversity, however, the absence of visual markers of race has led to a 'default Whiteness' in cyberspace, says Ms. Tal [a professor of humanities at the University of Arizona who studied representations of race in Internet-based discussions]. In other words, many Internet users assume that all other users they encounter are White, unless they are told otherwise. 'The problem began to emerge when people who were particularly activist about [their race] realized that in order to really be seen on the Internet, they had to keep saying, I'm black,' according to Ms. Tal. 'And then other people say, why are you always talking about race? The initial exhilaration is turning, for some people, into a pretty strong frustration,’ she adds. [44]

This online anonymity may impede the transference of culturally-based community preferences associated with African Americans to the classroom setting. Some racial and ethnic groups, such as African Americans, place higher emphasis on communal values, which include knowledge that is valued, how learning occurs, and communication patterns of working together for the good of community [45]. These values were widely noted and accepted in many African American learning communities as the values of Kwanzaa, a collection of African American tribal traditions that have been classified as spirituality, harmony, movement, verve, affect, communalism, expressive individualism, orality, and social time perspective [46]. While these attributes, values, and characteristics are not to be viewed as monolithic for an entire race of people, they have been proven valuable to note when educators are 
looking for pedagogical markers that differentiate the learning processes of African American groups who have little to no significant cultural contact with the learning patterns of other cultures [46, 47]. This view is consistent with the work of Treisman, who concluded that African American students performed better in college when they adopted the study group strategies of Asian populations, to include having clear expectations, engaging in regular study, collaboration, and review, and developing meta-cognitive skills and when students were encouraged to collaborate on challenging problems in an environment of high expectations [48]. The major implication for professors of African American students is to use a pedagogy that encourages Black students to explain their understanding of subject matter within a collaborative and cohesive group context. Although the course sampled in the present study included graded weekly group discussion topics, course assignments involved only independent work, which may have contributed to Black students possessing weaker sense of community and achieving lower grades than their White peers in the predominantly White ALN environment.

Instructors of African American students in distance education environments should also take note of the recommendations for teaching non-native speakers of English [49]. Such pedagogy is centered on: (a) using a constructivist approach to learning; (b) relating course materials to multiple social and cultural environments; (c) providing handouts to assist students; (d) encouraging intra-student dialogue in tandem with the instructor; and (e) arranging student study groups or research projects [49]. This pedagogy is consistent with the literature on effective learning styles for many African Americans [e.g., 47, 48, 50, 51]. Moreover, a qualitative study of African American women students who successfully completed a doctoral program at the Fielding Graduate Institute, a predominantly White university delivering courses at a distance, included the following recommendations:

- Encourage mentoring. The nature of the contact doctoral students have with their advisers and mentors appeared to have much influence on the nature of the experiences that they had at the distance education institute.

- Understand the social, economic, political, educational, and cultural effects that race has had and may continue to have on the lives of African American women.

- Encourage African American students to participate in leadership activities at the distance education institute [52].

The concept of schools as communities, each with its own school ethos and student support system, is particularly important in distance education, where student persistence and learning are issues and where mixed groups of students will have expectations arising from their own local communities that may differ with the accepted norms of schools from other communities.

\section{CONCLUDING REMARKS}

This study provides evidence that the achievement gap that has been reported in many traditional educational programs can also exist in graduate ALN programs and that this gap also extends to sense of community. Schools involved in distance education need to recognize that they have to do more than present courses at a distance. They need to also initiate changes in their own structures and practices to better meet the needs of their entire student bodies, integrate distant learners into their schools as they do with on-campus students, and foster a sense of school community among all students. This view is consistent with that of Palloff and Pratt, who wrote that "Even in this virtual or electronic community, educators must realize that the way the medium is used depends largely on human needs... and that these needs are the prime reason that electronic communities are formed” [32]. 
The professional literature suggests that the achievement gap can be closed by designing and presenting online courses that respond to the culturally-diverse backgrounds of all students. Future research should be directed at identifying collaborative and facilitative online instructional strategies that foster a sense of community and increase academic achievement among culturally diverse students. If we can determine how to increase sense of community among minority students in a predominantly White online learning environment, perhaps we can concentrate on forming strong classroom communities and rely on these communities to promote high achievement and persistence among all students.

The ability to generalize findings beyond the present study is limited because a single course at the same university taught by the same instructor was sampled and the learner characteristics, course content, course design, and pedagogy used by the professor may not be representative of other professors and other settings. Study results may not generalize to other distance education formats, such as televisionbased systems. Moreover, cause-and-effect relations were explored, not confirmed, in the present study.

The present research should be replicated in order to determine if findings are consistent across other samples, courses, course designs, and schools. Experimental research that attempts to identify optimal methods for promoting a strong sense of community should be performed-online and face-to-face environments should be compared and contrasted as well as undergraduate versus graduate education. Moreover, the research should be extended to further investigate and elucidate the relationships examined in the present study by changing methodological approach from canonical correlation analysis to structural equation modeling (SEM). The SEM approach would enable examination of various measurement models as an aid in selecting indicator variables, assessing construct reliability, and investigating differences among models that specify alternative hypotheses about the relationships among the constructs of interest.

Within the asserted study limitations, however, the present results suggest a positive relationship between sense of community and student learning in an asynchronous online environment, similar to previous research within traditional settings. For online instructors, this information spawns a crucial consideration when designing new courses. Only through continued research in this area will optimal strategies be identified and adopted that maximize the potential of online education.

The importance of asynchronous education will only increase as it provides a convenient option for the busy adult. Extracurricular roles as spouse, parent, caregiver, worker, or friend create situational impediments in attending courses with fixed time frames. However, convenience need not be antithetical to rigor. Educators that use asynchronous instruction should attempt to create strategies that optimize student engagement in performance requirements that not only improve student learning but also lifelong learning. The present study suggests that promoting a strong sense of community may help to maximize such engagement and ultimate achievement.

\section{REFERENCES}

1. Walts, T., and L. Lewis. Distance education at degree-granting postsecondary institutions: 20002001 (NCES No. 2003-017). Washington, DC: U.S. Department of Education, National Center for Educational Statistics, 2003.

2. Sikora, A. C., and C. D. Carroll. Postsecondary education descriptive analysis reports (NCES 2003-154). U.S. Department of Education, National Center for Education Statistics. Washington, DC: U.S. Government Printing Office, 2002. 
3. Williams, K., D. Goldstein, and J. Goldstein. Improving the study habits of minority students through Web-based courses. TechTrends 46(2): 21-28, 2002.

4. Diaz, D. P., and R. B. Cartnal. Student learning in two classes: Online distance learning and equivalent on-campus. College Teaching 47(4): 130-335, 1999.

5. Gee, D. G. The impact of students' preferred learning style variables in a distance education course: A case study. Portales, NM: Eastern New Mexico University, 1990. In ERIC - Education Resources Information Center. Identifier number ED 358836.

6. Irizarry, R. Self-efficacy and motivation effects on online psychology student retention. USDLA Journal 16(12): 55-64, 2002.

7. Tinto, V. Leaving College: Rethinking the Causes and Cures of Student Attrition. Chicago: University of Chicago Press, 1993.

8. Cokley, K. O. What do we know about the motivation of African American students? Challenging the 'Anti-Intellectual' myth. Harvard Educational Review 73(4): 524-558, 2003.

9. Ogbu, J. U. Understanding cultural diversity and learning. In J. A. Banks \& C. A. McGee-Banks (eds.), Handbook of Research on Multicultural Education, 582-593. Jossey-Bass: San Francisco, 1995.

10. Bennett, C. I. Comprehensive multicultural education: Theory and practice. Boston: Allyn and Bacon, 1986.

11. Hale-Benson, J. Black Children: Their Roots, Culture and Learning Styles. Provo, UT: Brigham Young University Press, 1982.

12. Kuykendall, C. Improving Black Student Achievement by Enhancing Students' Self Image. Chevy Chase, MD: The Mid-Atlantic Equity Center, 1989.

13. Shade, B. Afro-American cognitive style: A variable in school success. Review of Educational Research 52(2): 219-244, 1982.

14. Witkin, H. A., C. A. Moore, D. R. Goodenough, and P. W. Cox. Field-dependent and fieldindependent cognitive styles and their educational implications. Review of Educational Research 47(1): 1-64, 1977.

15. Bandura, A. Self-efficacy: The Exercise of Control. New York: W. H. Freeman and Company, 1997.

16. Bandura, A. Social Foundations of Thought and Action: A Social Cognitive Theory. Englewood Cliffs, NJ: Prentice Hall, 1986.

17. Pajares, F., and D. H. Schunk. Self-beliefs and school success: Self-efficacy, self-concept, and school achievement. In R. Riding \& S. Rayner (eds.), Perception, 239-266. Ablex Publishing: London, 2001.

18. Sergiovanni, T. J. Building Community in Schools. New York: Jossey-Bass, 1994.

19. Rheingold, H. The Virtual Community: Homesteading the Electronic Frontier. Reading, MA: Addison-Wesley, 1993.

20. Dede, C. The evolution of distance education: Emerging technologies and distributed learning. The American Journal of Distance Education 10(2): 4-36, 1996.

21. Wellman, B., and M. Gulia. The network basis of social support: A network is more than the sum of its ties. In B. Wellman (ed.), Networks in the Global Village, , 83-118. Westview Press: Boulder, CO, 1999.

22. Bryk, A. S., and M. E. Driscoll. The high school as community: Contextual influences and consequences for students and teachers. Madison, Wisconsin: National Center on Effective Secondary Schools, University of Wisconsin, 1988. In ERIC - Education Resources Information Center. Identifier number ED 302539.

23. Royal, M. A., and R. J. Rossi. Individual-level correlates of sense of community: Findings from workplace and school. Journal of Community Psychology 24(4): 395-416, 1996.

24. Brookfield, S. D. The Skillful Teacher. San Francisco: Jossey-Bass, 1990.

25. Biehler, R. F., and J. Snowman. Psychology Applied to Teaching (6 $6^{\text {th }}$ ed.). Boston: Houghton Mifflin, 1990. 
26. Lave, J., and E. Wenger. Situated Learning: Legitimate Peripheral Participation. Cambridge, MA: Cambridge University Press, 1991.

27. Rogoff, B. Developing understanding of the idea of communities of learners. Mind, Culture, and Activity 1(4): 209-229, 1994.

28. Wenger, E., R. McDermott, and W. M. Snyder. Cultivating Communities of Practice: A Guide to Managing Knowledge. Boston: Harvard Business School Press, 2002.

29. Baym, N. K. The emergence of community in computer-mediated communication. In S. Jones (ed.), CyberSociety: Computer-mediated Communication and Community, 138-163. Sage: Thousand Oaks, CA, 1995.

30. Donath, J. S. Identity and deception in the virtual community. In M. A. Smith, and P. Kollock (eds.), Communities in Cyberspace, 29-59. Routledge: New York, 1999.

31. Sproull, L., and S. Kiesler. Connections: New Ways of Working in the Networked Organization. Cambridge, MA: The MIT Press, 1991.

32. Palloff, R., and K. Pratt. Building Learning Communities in Cyberspace: Effective Strategies for the Online Slassroom. San Francisco: Jossey-Bass, 1999.

33. Jonassen, D., M. Davidson, C. Collins, J. Campbell, and B. B. Haag. Constructivism and computer-mediated communication in distance education. The American Journal of Distance Education 9(2): 7-26, 1995.

34. Grasha, A. F. Teaching with style: The integration of teaching and learning styles in the classroom. Innovator 3(1): 3-4, 1997.

35. Rovai, A. P. Development of an instrument to measure classroom community. Internet and Higher Education 5(3): 197-211, 2002.

36. Hiltz, S. R., and B. Wellman. Asynchronous learning networks as a virtual classroom. Communications of the ACM 40(9): 44-49, 1997.

37. Corrallo, S. The progress of a study identifying the speaking and communication skills of college graduates. In S. Morreale and M. Brooks (eds.), 1994 NCA summer conference proceedings and prepared remarks: Assessing college student competency in speech communication. National Communication Association: Annandale, VA, 51-54, 1994.

38. Richmond, V. P., J. S. Gorham, and J.C McCroskey. The relationship between selected immediacy behaviors and cognitive learning. In M. A. McLaughlin (ed.), Communication Yearbook 10, 574-590. Sage: Newbury Park, CA, 1987.

39. McCroskey, J. C, A. Sallinen, J. M. Fayer, V. P. Richmond, and R. A. Barraclough. Nonverbal immediacy and cognitive learning: A cross-cultural investigation. Communication Education 45(3): 200-211, 1996.

40. Cohen, J. Statistical power analysis for the behavioral sciences (revised edition). New York: Academic Press, 1977.

41. Ponton, M. K., and P. B. Carr. Understanding and promoting autonomy in self-directed learning. Current Research in Social Psychology 5(19): 271-284, 2000.

42. Schwartz, W. Closing the achievement gap: Principles for improving the educational success of all students. New York: ERIC Clearinghouse on Urban Education, Identifier number ED 460191, 2000.

43. Russell, T. L. No significant difference phenomenon. Raleigh, NC: North Carolina State University, 1999.

44. Young, J. Scholars question the image of the Internet as a race-free utopia. The Chronicle of Higher Education A48: September 28, 2001.

45. Flannery, D. D. Adult education and the politics of the theoretical text. In B. Kanpol and P. McLaren (eds.), Critical Multiculturalism: Uncommon Voices in a Common StruggleI, 149-163. Bergin and Garvey: Westport, CT, 1995.

46. Boykin, W. The triple quandary and the schooling of Afro-American children. In U. Neisser (ed.), The School Achievement of Minority Children: New Perspectives, 57-91. Erlbaum: Hillsdale, NJ, 1986. 
47. Hale, J. E. Learning While Black: Creating Educational Excellence for African American Children. Baltimore: The John Hopkins University Press, 2001.

48. Treisman, U. A study of the mathematics performance of black students at the University of California, Berkeley. Doctoral dissertation, University of California, Berkeley, Proquest Digital Dissertations, No. AAT 8610244, 1986.

49. Williams, K., D. Goldstein, and J. Goldstein. Improving the study habits of minority students through Web-based courses. TechTrends 46(2): 21-28, 2002.

50. Delpit, L. Other People's Children: Cultural Conflict in the Classroom. New York: New Press, 1995.

51. Ladson-Billings, G. The Dreamkeepers: Successful Teachers for African American Children. San Francisco: Jossey-Bass, 1994.

52. Ford, C. R. Whatever it takes: The experience of African American women doctoral students at a distance learning institution. Doctoral dissertation, Fielding Graduate Institute, Proquest Digital Dissertations, No. AAT 3080220, 2003.

\section{ABOUT THE AUTHORS}

Fred Rovai, $\mathrm{PhD}$ and Michael Ponton, EdD are professors at the School of Education at Regent University in southeastern Virginia. Fred's major research interests are distance education, sense of community, and learning while Michael's interests are in the field of adult education. They both teach in a mostly online Doctor of Education program. 